\title{
Reconsidering Dignity Relationally
}

\section{Sarah Clark Miller}

To cite this article: Sarah Clark Miller (2017) Reconsidering Dignity Relationally, Ethics and Social Welfare, 11:2, 108-121

To link to this article: http://dx.doi.org/10.1080/17496535.2017.1318411

\section{Published online: 24 May 2017.}

Submit your article to this journal $\widetilde{ }$

Q View related articles $\sqsubset$

View Crossmark data $\nearrow$ 


\title{
Reconsidering Dignity Relationally
}

\author{
Sarah Clark Miller
}

The Pennsylvania State University, University Park, PA, USA

\begin{abstract}
I reconsider the concept of dignity in several ways in this article. My primary aim is to move dignity in a more relational direction, drawing on care ethics to do so. After analyzing the power and perils of dignity and tracing its rhetorical, academic, and historical influence, I discuss three interventions that care ethics can make into the dignity discourse. The first intervention involves an understanding of the ways in which care can be dignifying. The second intervention examines whether the capacity to care should be considered a distinguishing moral power - as rationality often is - in light of which humans have dignity. In the third intervention, I cast dignity as a fundamentally relational concept and argue that relationality is constitutive not only of dignity but also of the wider enterprise of normativity. I understand relationality as the condition of connection in which all human beings stand with some other human beings. A thought experiment involving the last person on earth helps to reframe the normative significance of human relatedness. Dignity emerges as fundamentally grounded in relationality.
\end{abstract}

\section{KEYWORDS}

Dignity; relationality; care; care ethics

In the pages that follow, I reconsider the concept of dignity in several regards with the aim of moving it in a more relational direction. The primary philosophical resource I draw on to do so is care ethics. The power and perils of dignity will be my first topic, in the introduction, where I also introduce a key distinction that will govern the rest of the discussion. Three interventions care ethics can make into the dignity discourse will follow. The first intervention involves an understanding of the ways in which care can be dignifying. The second intervention brings attention to how the ability to care might function as a distinguishing moral power. The third intervention is perhaps the most groundbreaking: in it I cast dignity itself as a fundamentally relational concept.

\section{Introduction}

We might begin by asking a question, the response to which hopefully justifies the very existence of this project: Why is dignity an important philosophical issue to consider? The process of answering this question reveals dignity to be both a highly influential and a profoundly problematic concept. 
Dignity wields considerable political, ethical, intellectual, and perhaps ultimately, rhetorical force. We need look no further than the United Nation's Universal Declaration of Human Rights, which begins with the claim that 'recognition of the inherent dignity and of the equal and inalienable rights of all members of the human family is the foundation of freedom, justice and peace in the world'. ${ }^{1}$ Here dignity launches human rights in the eyes of the United Nations and serves as that which grounds nothing less than freedom, justice, and peace the world over.

Dignity wields considerable force within the academy, too. For scholars not situated in the discipline of philosophy, it may be useful to note that dignity continues to figure prominently in ethical and political theory, both in the context of Kantian ethics and in broader, thematic domains. Kantian ethics functions as the subfield in which discussions of dignity are perhaps most prevalent, as well as the field that holds the most influence over the dignity discourse within philosophy (with one commentator charging that this hold amounts to a 'conceptual hegemony over dignity' (Debes 2009, 49)). Dignity also plays a prominent role in Martha Nussbaum's capability approach, especially in her more recent work, Frontiers of Justice (2006 and discussed in Claassen 2014; Formosa and Mackenzie 2014). In addition, the concept of dignity as equal moral worth appears throughout the literature on cosmopolitan justice - lending crucial argumentative support at key moments (Moellendorf 2002; Nussbaum 2006; Van Hooft 2009).

In related academic domains, there has been a recent reassertion of the relevance of dignity. In bioethics, literature of the past several years has affirmed the importance of dignity - a concept that has found recurrent prevalence in this discipline - for example, in the work of Charles Foster (2011), who names dignity as an essential and, in fact, the only principle for bioethics. Roberto Andorno (2013) features the concept in arguing that we can bring greater clarity to the use of dignity in bioethics by distinguishing between two different roles it plays therein: as a policy principle and as a standard of patient care. In sociology, Barbara Misztal (2013) explores dignity's modern significance for sociological theorizing, including contributions the concept can make to discussions about respect, self-worth, and intersubjective recognition. Misztal also considers what the discipline of sociology might contribute to the evolving meaning of the concept, especially in terms of the ongoing conversation about the intersections of dignity, justice, and human rights $(2013,118)$. A final pair of examples comes from legal theory. In recent work, Jacob Weinrib (2016) explores the significance of dignity for constitutional law. And in Harmful Thoughts (2002), Meir Dan-Cohen argues for a shift in legal theory from harm to dignity. More specifically, Dan-Cohen suggests that liberal criminal law theory move from the dominance of the harm principle not to the alternative of autonomy (as one might expect) but instead to the morality of dignity. While there are additional examples one might include, this sample will hopefully suffice in providing a general sense of the sustained, and in some cases reemerging, interest in dignity in multiple disciplines.

Historically speaking, the meaning of dignity has been far from static. We can track the evolution of its meaning over time by examining three different epochs and their accompanying transformations in meaning. In the time of Cicero, dignity referred to something like nobility or social class. We can think of this as the notion of merit in terms of social standing. In the Judeo-Christian tradition, and in the tradition of Augustine, humans were made in the image of God, with God serving as the ultimate source of human 
dignity. Within the Enlightenment tradition, and most notably in the philosophy of Immanuel Kant, dignity comes to mean rational agency or autonomy. More narrowly and specifically, it means moral self-legislation or the ability to give the moral law to oneself. While at present, there are multiple meanings of dignity in play culturally, that which figures most prominently in philosophical circles remains the Kantian concept of dignity.

\section{Four problems with dignity}

In addition to being an historically shifting concept, dignity is also, it turns out, a highly problematic one. Complaints against dignity are wide-ranging and cover everything from its general uselessness to its exclusionary nature. I will examine four such complaints here.

First is the complaint that dignity is a concept that is at best ambiguous and at worst useless. Ruth Macklin articulates these concerns in an article with the very direct title of 'Dignity Is a Useless Concept' (2003). Macklin proclaims the uselessness of dignity on two accounts: (1) that it represents a vague reworking of other, more philosophically useful and precise concepts and (2) that it amounts to nothing more than an empty slogan-related call for action, without any real meaning $(2003,1419)$. The more precise concept that she favors and which she feels many references to dignity boil down to is respect for autonomy. Because of its widespread ambiguous usage and the way in which it is often called upon to evoke expansive and imprecise ideas, Macklin ultimately holds that dignity lacks any abiding meaningfulness.

Next is the charge that dignity is an ineffectual concept. Those suspicious about dignity's effectiveness include anti-, post-, and decolonial theorists. Take, for example, the following powerful assertion Frantz Fanon makes in Black Skin, White Masks: 'I do not carry innocence to the point of believing that appeals to reason or to respect for human dignity can alter reality. For the Negro who works on a sugar plantation in Le Robert, there is only one solution: to fight' $(2008,224)$. Fanon judges dignity to be utterly impotent against the powers and interests of oppression and, moreover, as a tool of revolution. Resistance - physical and otherwise - must accomplish what appeals to dignity cannot and never will.

A related third criticism: multiple theorists interested in issues of race, class, gender, and disability have, in different, yet related ways, found themselves suspicious of the theoretical construction of the notion of dignity. They have rightfully questioned, on the one hand, who that concept has tended to include and benefit and, on the other hand, who has been excluded from its circle. For these theorists, dignity is an overwhelmingly white, Western, male, and able-bodied notion. This is true in at least two specific regards. The identities of the philosophers and related intellectuals who historically have tended to articulate the importance of dignity have fit this profile. Beyond the identity of those originating the concept, dignity has also seemed exceedingly white, Western, male, and able-bodied in its execution, that is, in how it has been practically employed as a governing concept in social, legal, and political contexts. Citation of the dignity of humanity can render various identities, as well as the intersectional forms of oppression that weave through socially situated identities, invisible. For example, theorists working on intellectual disability, such as Martha Nussbaum (2009) and Eva Feder Kittay and Licia Carlson (2010), have challenged the exclusion of persons with certain cognitive disabilities from the circle of 
dignity because of how they purportedly do not meet the rationality requirement at the core of many standard accounts of dignity.

Dignity as a concept has also traditionally excluded non-human animals. In line with this concern, we might see dignity as a fine story we tell ourselves, one that conveniently locates humans at the center of moral considerability - which seems at least self-congratulatory and suspicious given that humans are the ones doing the considering. Thus, nonhuman animals have often been excluded as direct bearers of dignity (though treating them respectfully has sometimes been required as an indirect duty in order to respect the dignity of the person who 'owns' them, as is true in Kant's moral philosophy).

The final concern addresses not so much the content of dignity, as its foundation. While the concept of dignity often arises in philosophical work, the claim here is that the ground for dignity, that is, its normative foundation, often remains uncertain and inadequately delineated. This level and kind of complaint can ultimately be read and met as a call for a clearer, more developed metaethics of dignity. At the end of this article, I will offer one specific response to this call inspired by relational ethics and the ethics of care.

An amalgamated expression of these four concerns sounds this way: while dignity remains a vitally important concept, its contents are ambiguous, underdetermined, and inadequately examined, resulting in its status as a concept that is, at turns, useless, meaningless, ineffectual, biased, and ungrounded. How are philosophers to respond to both the deep skepticism regarding the grounding, content, and function of this concept, as well as its considerable historical variance? Can we determine (1) What dignity actually is, and, moreover, (2) Why we think we have it? To elaborate further, we might ask, What exactly is dignity, both in terms of form (i.e. metaethically speaking) and in terms of content and deployment (i.e. normatively or practically speaking)? Is it something that is properly ascribed of human beings, and if so, why?

Having provided a general sense of the landscape of criticism of the concept of dignity, my goal in the remainder of this article will be to focus on a few individual features of that landscape. I do so by considering the specific theoretical contributions care ethics and relational ethics can provide for fostering both further understanding of and response to some of these criticisms. These contributions will take the form of three primary interventions into the dignity debate. Care ethics is a theoretical framework particularly wellsuited to accomplish an overarching aim of this article, namely, to explore how remaking and advancing dignity in a less individualistic and more relational fashion might improve the concept. This is because of the focus care ethics sustains on the significance of relationships and relationality for ethical life. In addition, philosophers have not tended to draw on care ethics when discussing dignity, making this line of inquiry a potentially fresh one. For these reasons, care ethics stands to make a distinctive and valuable contribution to this discussion. The field of care ethics has grown since it first appeared in the 1980 s and now offers multiple varieties for philosophical consideration. The particular subspecies of care ethics that I employ here is deontological care ethics, an approach I previously developed at length in The Ethics of Need (Miller 2012). This version of care ethics fashions a synergistic relationship between Kantian ethics and care ethics, mapping the interaction between ethics as caring and ethics as dignity. (I describe this approach in greater detail below.) With regard to the current task at hand, Kant's influence on Western discussions of dignity cannot be underestimated and, as such, a Kantian 
variety of care ethics could prove particularly helpful for developing the discourse on dignity further. Or at least that is the hope.

A final note before presenting the three interventions: a key distinction will govern the discussion here. This is the distinction between two kinds of dignity or two different ways in which philosophers tend to employ the concept. The first kind of dignity we might call performative dignity. This is dignity as recognized through moral other- and self-regard, that is, a quality that can be acknowledged through how others treat us morally and also through how we treat ourselves. This kind of dignity falls squarely in the terrain of normative ethics. What care ethics will add to this form of dignity is an emphasis on care's interaction with the expressive function of dignity. This constitutes the first intervention that I offer. The second kind of dignity is what we might call status dignity. This is dignity as unearned, intrinsic moral worth. With status dignity, dignity functions not so much as a normative concept as it does a foundational or metaethical concept. In conjunction with status dignity, relational and care ethics will add an emphasis on relational capacities and relational ontology, that is, on the very relational nature of dignity itself. ${ }^{2}$ Discussion of these points comprises interventions II and III.

A well-known distinction in the philosophical literature intersects in interesting ways with this discussion, namely, Stephen Darwall's distinction between recognition respect and appraisal respect, which he discusses in his 1977 article, 'Two Kinds of Respect' (1977). Recognition respect refers to a disposition one has to give appropriate weight or consideration to a person (or other appropriate object) when conducting one's moral deliberations. Recognition respect informs both one's deliberations about another and how one then decides to act toward that other. Appraisal respect, on the other hand, refers to a positive attitude one holds toward another person one has judged to have an excellent moral character.

What is perhaps most important to note is that recognition and appraisal respect represent two sub-varieties of respect as an attitude or disposition that a moral agent holds toward others. In contrast, dignity in my account is not an attitude or disposition but instead a property a person has. While we might first think that these two different approaches (Darwall's and my own) run parallel to one another, this is ultimately incorrect. Instead, the two different approaches intersect in the following fashion. What I, following others, am calling status dignity would be the proper object of the disposition of recognition respect. Status dignity, as essentially inherent moral worth, is that which one recognizes through recognition respect. A similar intersection, however, does not exist between performative dignity and appraisal respect. We cannot say that one variety of performative dignity would be the proper object of appraisal respect. As we will see, performative dignity as it functions in conjunction with care is not a matter of judgment of someone's character.

\section{Three interventions}

Rarely have the concepts of care and dignity been considered together. This is perhaps because of the strong association between dignity and Kantian ethics and the sometimes allergic reaction of care ethicists to Kant - specifically to his duty-laden variety of moral life. There are, however, a few exceptions to this general rule, found in the work of Robin Dillon (1992), Daniel Engster (2004), Eva Feder Kittay (2011), and Carlo Leget (2013), each of whom analyze possible philosophical interactions between care and dignity. 
Given the relative lack of integrative consideration of the concepts of care and dignity, I bring them together in three different ways in this article, which I have conceptualized as three interventions that care ethics can make into the current discourse and historical legacy of dignity. The first two are found in the register of normative ethics. The third is a form of metaethical inquiry. They are: (1) Intervention I: care as dignifying; (2) Intervention II: the moral power of care; and (3) Intervention III: dignity as fundamentally relational.

\section{Intervention I: care as dignifying}

In this first intervention, I bring care and dignity together by analyzing the role that dignity might play in any caregiving scenario and highlighting an underappreciated aspect of the ethical work that care might do vis-à-vis dignity in such contexts. This is the idea that good care can be dignifying, a concept that I introduced briefly in The Ethics of Need (Miller 2012) and develop further here.

A commonly overlooked aspect of care is its performative or expressive function. When we care well for others, we acknowledge and highlight their inherent worth and dignity. We recognize, represent, and reflect their value back to them, to ourselves, and to others who stand in social relation with them. Care that is dignifying in this way does not originate dignity in others. Dignity as inherent worth and value is already present in those cared for. Thus, good care acknowledges and preserves something that is already there. This is a vitally important point and one that is sometimes misunderstood: care as performative or expressive cannot establish status dignity or dignity as fundamental or inherent worth. Worth that is inherent can neither be given nor taken away. If someone were only to ever be the recipient of terribly inadequate and bad care, they would still have inherent worth and dignity. But good care can magnify, nurture, and promote the dignity of others. Note also that to focus on the ways in which caring well for others has a performative or expressive function does not render the one receiving care passive. They are still fully empowered not only to accept or reject the care offered to them but also, more generally, to shape how others perceive their moral worth. To focus on the expressive function of care and how this affects the perceived moral worth of the cared for is thus only to focus on one moment of a broader ethical relationship and is not meant to circumscribe the agency of those receiving care.

A useful way to think about the performative impact of care is in conjunction with the idea of moral regard. Our actions have an expressive function that interacts with the perceived worth of others - both in terms of how they perceive themselves and how others perceive them. Our actions correspond with and can display our attitudes. As we have seen, respect is most often the attitude discussed in conjunction with dignity. Though more often characterized in the literature as a capacity or ability, care also embodies an important and related attitude - the attitude of caring regard. Respect functions as a certain form of acknowledgment of or regard for a person's dignity. What I am suggesting is that good care functions similarly - acknowledging another's dignity, though perhaps in a different register or key.

It is illuminating to parse the several differences that are simultaneously in play between care as an attitude and respect as an attitude. The form of acknowledgment differs - expressing the attitude of respect is not the same thing as expressing the attitude 
of care. Kant's rather dramatic characterization of love and respect in terms of natural forces in the The Metaphysics of Morals is relevant here:

In speaking of the laws of duty (not laws of nature) and, among these, of laws for human beings' external relations with one another, we consider ourselves in a moral (intelligible) world where, by analogy with the physical world, attraction and repulsion bind together rational beings (on earth). The principle of mutual love admonishes them constantly to come closer to one another; that of the respect they owe one another, to keep themselves at a distance from one another; and should one of these great forces fail, 'then nothingness (immorality), with gaping throat, would drink up the whole kingdom of (moral) beings like a drop of water)' (if I may use Haller's words, but in a different connection). (1996, 198-199, [MS 6: 449], emphasis in the original)

Following this Kantian spirit, we can understand the relationship between respect, care, and moral worth as such: Respect is an attitudinal recognition of another's dignity that, in terms of action, keeps us from interfering with their life plans and goals. To be sure, this is not the sole mode of action that respect encourages, but is, at least, a prominent one. Care, in contrast, is an attitudinal recognition of another's dignity, but one that encourages the action of the carer stepping in to support the life plans of the one for whom they are caring. (I will comment further on the action aspect of this formula in the discussion of Intervention II.) $)^{3}$ We can summarize the difference between the two attitudes as follows: while that which the attitudes of respect and care acknowledge is the same - that is, another's dignity as inherent moral worth - they differ both in terms of the form the acknowledgment takes and the actions the attitudinal recognition encourages.

Not all care, however, is good care. Considering how both care that is adequate and care that is insufficient function can help us to see clearly how good care might be dignifying, whereas bad care is destructive of the acknowledgment of dignity in another. Both good care as an attitude and care as the actions that then accompany it can bring about the further expression of dignity in a person in the sense of augmenting both the moral regard others have for them as well as their moral self-regard. Care that is good affirms the inherent dignity of the person cared for, often with the concomitant outcome of supporting those in need in their agency and in flourishing. Care that is insufficient or bad is most often understood as care that fails to meet the expressed or implicit needs of the care receiver. This is one major way care can fail as an action. As we have been acknowledging, however, the attitude of care is as vital to the moral interaction as is the action. So what does bad care that is expressed in terms of attitude look like? A person can have their needs met, but have them met in a way that expressively or performatively damages their dignity as a self-conception or in the eyes of others. A care recipient, through actions of the caregiver, can be represented as having lower moral worth or standing than they do. How we meet others' needs is just as morally significant as that we meet them. We can think of this as the moral importance of the manner of meeting needs.

\section{Intervention II: the moral power of care}

With the second intervention, we move from care as attitude to care as action and even more pertinently, to care conceptualized as a distinctive moral power. Intervention II asks us to reconsider that in light of which we understand ourselves to have dignity. While there are multiple capacities in virtue of which humans have historically been thought 
to have dignity, rationality is undeniably the dominant conception. For Kant, of course, dignity inheres in the moral importance of human beings' rational agency, that is, in their rational end setting ability. This rational ability is what, for Kant, distinguishes persons in their humanity from their animality. Persons are free and rational beings (of the finite variety) and have the power to set their own ends. Human beings have inherent worth in light of their power of rational self-determination.

Intervention II asks us to examine the possibility that care, much like rationality, might serve as a distinctive moral power, one indicative of the inherent worth and dignity of humanity. While the capacity to care has not historically been considered as a distinguishing moral ability, I am suggesting that this may be a significant oversight. In order to assess whether care might so qualify, we need first to understand what exactly comprises the ability to care, especially in this specific context.

Within the care ethics literature, philosophers often define care as a response to one of three aspects of the human condition: human need (Tronto 1993; Engster 2007), vulnerability (Goodin 1985; Ruddick 1989), and/or dependency (Bubeck 1995; Kittay 1999). While my intention here is not to provide a schema of the history of definitions of care, we can note that care ethicists can differ from one another in taking one or the other of these shared aspects of our humanity to be foundational to care. And, indeed, still others define care in ways that exceed the tripartite characterization above. The nature of this response to human need, vulnerability, and/or dependency is frequently understood to be infused with emotional attentiveness. Care is thus often (though not always) a series of actions paired with a certain affective engagement (Noddings 1984; Baier 1987; Bubeck 1995). The way I approach care, while indebted to this tradition, differs from it in certain key ways. My approach starts from the idea that the requirement to feel certain emotions cannot function as a proper object of obligation. Our emotions fluctuate in ways that are unpredictable and over which we have limited control. We cannot be obligated to feel things that are subject to a fundamental fluctuation that in some way is beyond us. Because emotions cannot be morally required, I focus on care as action, rather than as emotion.

Thus, on my account, care is the distinctive capacity that humans have to perceive, understand, adopt, and advance another person's self-determined ends as their own. This is done in support of the happiness and well-being of the one cared for. Caring well for others involves promoting their well-being by first understanding what they believe contributes to their own well-being and then responding to them through a framework that prioritizes their self-understanding. In this scenario, carers maintain their own overarching life goals. Care in this sense is not the promotion of self-sacrifice or of living vicariously through another's ends. To care well, however, carers must take seriously the ends that are important to those for whom they care. Instead of imposing what the carers may think is best for the cared for, carers must respect their self-determination. In short, this is the ability to care for others by adopting and advancing their self-determined ends as our own. This is the moral power of care.

In Kantian language, from which, perhaps counterintuitively, this idea initially hails, this is the core of practical love or beneficence, when we adopt and advance another's selfdetermined ends as our own. Kant famously maintained that humanity is deserving of respect in light of the capacity to set ends in accordance with reasons. Similarly, I want to consider the possibility that we might recognize humanity as deserving of a special 
form of moral regard because of our ability to care. Rationality has often been characterized as something like a unique moral power. Ought we consider caring, in the way I am defining it here, to be a similarly unique moral capacity?

To be clear, this approach does not amount to a denigration of the moral importance of emotions. To my mind, they have a proper place at the center of any moral life worth living. But while they can be cultivated, specific emotions cannot be required. As such, moral requirements must attach to another sort of entity, that is, action (and possibly attitudes, but that is a matter for another day). I therefore render the moral ability to care a matter solely of action.

The idea of care as a distinctive moral power that I am proposing here, however, entails a more robust picture of moral action than what we standardly think rational action involves. We can see this in considering what moral agents need in order to perform the action of effectively comprehending, adopting, and advancing others' ends. While rationality plays a role in this process, it must necessarily share the stage with other capacities. Foremost among other required abilities are social or relational and emotional abilities. Moral agents are likely to do a better job of caring for others if that caring involves understanding informed by all three of our rational, emotional, and relational abilities. The inclusion of the emotional here does not amount to a moral requirement to feel a certain way (which, as I state above, is an impossibility), but rather highlights a general need to cultivate the emotional capacities involved in caring (cf. Sevenhuijsen 1998; Slote 2007).

It turns out, however, that the second intervention I have proposed may fall prey to a serious objection. Rendering the moral power of care as the key to a capacity-based account of dignity may be an improvement on rationality - or at least an interesting expansion. Such an ascription of value, however, potentially excludes certain members of the human circle, not to mention non-human animals. On this account, value is accorded in conjunction with the ability to care, an ability that not all humans have. I have argued that humans could be considered to have dignity not only because they possess powers of rationality but also because they possess powers of caring, thus potentially acknowledging another capacity in light of which we have moral standing. But, in short, this expanded understanding of what distinguishes humanity morally could exclude other humans from qualifying as beings with dignity.

Just as rationality is found to a greater or lesser extent in various humans - as well as wavering from moment to moment in terms of the degree to which individual humans exercise it - so too with caring. And just as skills of rationality can be cultivated, so too, can skills of caring. In fact, one benefit of identifying care as a distinctive moral power equal in rank to rationality could be increased attention to the importance of cultivating and possessing the ability to care, which could challenge gendered, social expectations in many cultures that women will do the lion's share of the caring, a point that certainly has not been lost on multiple care ethicists. Yet not all humans are able to care. Perceiving and advancing another's self-determined ends as one's own requires abilities that will forever exceed the grasp of some human beings. Those with severe cognitive and affective impairments may never evidence the moral power of care. Thus, the argument that humanity might be deserving of dignity because of its caring abilities encounters an objection to which any capacity-based account of human moral worth is vulnerable: it potentially excludes some human beings from the circle of full moral consideration. In essence, it violates a principle of equal moral standing. 
While there may be other ways to secure the moral standing of those with limited cognitive and affective capacities in the human community - for example, by recognizing that caring as a typically human ability grants dignity to all humans - the potential exclusion of them from this approach renders it one that is ultimately inadequate. Thus, I offer another, hopefully more satisfying, approach in Intervention III, one that grounds our moral standing in our fundamental relationality.

\section{Intervention III: dignity as fundamentally relational}

More so than most other philosophical approaches, care ethics is focused on the significance of relationships and the relational for our moral lives (Metz and Miller 2016). One need only think of the origins of this moral philosophy for evidence of this claim. The 'different voice' that Carol Gilligan discovered and featured was one that sought to preserve relationships by limiting the harm done to them (1982). A main focal point of $\mathrm{Nel}$ Noddings' Caring (1984) is, of course, the caring relationship. And Sara Ruddick mined the maternal relation in Maternal Thinking (1989), in which 'maternal persons' may be of any gender, to develop not only modes of moral reasoning but also the foundation for a politics of peace. Care ethicists' strong interest in the relational has continued in recent years, for example, with the focus on the dependency relation that some care ethicists have taken (Kittay 1999) and on possibilities for caring global relations (Held 2006).

In contrast to the often-relational stance of care ethics, theories of dignity are ultimately focused on the individual. Dignity inheres in individuals, not groups, and does so on most, if not all, theories of dignity because of the capacities or qualities of the individual in question, usually rationality. With this third intervention, I bring care ethics to bear on theories of dignity by asking what significance relationality might have for dignity. More specifically, I aim to investigate whether dignity might be rendered a fundamentally relational concept and what it would mean if this were the case. The idea here is one that moves dignity away from an implicitly individualist foundation towards something more decidedly relational. Taking the line of inquiry one step further, we could ask: might relationality be foundational for dignity?

There are certain ways in which philosophers already commonly understand dignity to be relational. For example, in discussing the concept of status dignity, Paul Formosa and Catriona Mackenzie note that '[a]s a status-term, dignity is relational. Those who have dignity are elevated over those who lack dignity (all else being equal)' $(2014,877$, emphasis in the original). In this understanding of 'relational', dignity is relational because it is a concept placing people in comparative relation with one another. While this notion seems correct, it is not what I have in mind in describing dignity as relational or in considering the normative and foundational significance of relationality for dignity.

My investigation into relationality instead concerns the role that relationality plays in the conditions of the possibility of dignity itself. In this sense, it is an investigation into whether we can understand relationality to play a constitutive role for dignity, and, indeed, a constitutive role for normativity, as well. These are the two distinct senses in which we could take relationality to be foundational for both dignity and normativity that is, for the idea not only that humans have equal moral worth but also that humans are morally required to engage in certain actions and forbidden from performing others. 
Thus, ultimately, the claims I wish to make about dignity stem from even more fundamental assertions about normativity. Philosophers, in general, and ethicists, in particular, have tended to overlook and underappreciate the significance of human relationality for normativity. This is to say that in focusing on the moral significance of the individual, they have failed to fully investigate and appreciate the moral significance of the relationality humans enjoy. By relationality, I mean to refer to the condition of connection in which all human beings stand with some other human beings. Thus, I am here distinguishing between the condition of connection and the capacity of relationality, that is, the capacity of caring, which I explored in Intervention II. This condition holds even for human beings who are utterly isolated, as they were born of a human being, came to be the people they are through interactions marked and regulated by intersubjectivity, and presumably recall the relatedness that served to form them and that continues to occupy significant portions of their lives. Our very selves can, in these ways, be thought to be deeply relational. We are formed and sustained in and through modes of human connection. Through relationality and modes of human relatedness, we, in turn, form and sustain others.

In examining the significance of relationality for both normativity and dignity as foundational, a series of claims emerge. I will consider these claims by exploring a thought experiment designed to highlight the deep relationality of dignity and normativity. It aims to consider the normative significance of relationality by contemplating its absence.

The last human being on earth gets knocked on the head by a falling rock, suffering from amnesia. As a result, while he is still rational and enjoys the full range of human affective capacities, he does not remember ever having had relationships, that is, ever having been in relation with others. We can say that he does not stand in relation with others, be they human or non-human animals, either in fact (as he is the last person on earth) or in concept (in his head, so to speak - in memory or in projection of future possibilities and experiences). With the amnesia wiping away all memory of relatedness, he himself is no longer aware of being relationally situated and no others are present to experience him as such or remember when he was. Does this last person on earth have dignity?

I would argue that absent the condition of relationality, he does not. As you can likely tell, the intention behind this thought experiment is to create a scenario in which a person is human in nearly all the ways that we understand ourselves to be human, with the key exception that relationality no longer holds - either practically or conceptually. Does dignity survive a void of relationality? Does normativity? I do not believe that either does. There are three key moments of breakdown that ensue in the absence of the condition of relationality. They concern: (1) self-conception and self-understanding, (2) normativity, and (3) dignity.

Absent relationships with others, we humans have a difficult time making sense of ourselves. We are reliant upon other people to form an understanding of who we are. Development of self-understanding is a necessarily intersubjective process. We are incapable of achieving full self-awareness without the relationships we stand in with others. Beyond the developmental point, we rely on others to continue to make sense of ourselves to ourselves.

In addition, and as a parallel point, absent practical and conceptual relationality, we also cannot make much sense of normativity. To put this point even more strongly and, I believe, more accurately, under these conditions, normativity evaporates. Normativity is necessarily a relational enterprise. The condition of the relation - of standing in relation 
to another - is the condition of the possibility of normativity. Certainly, there can be moments in which we find ourselves alone and in which normativity continues - the point is not that we must at all times stand in direct and literal relation with another. This, however, is not the plight that befalls our last person on earth. He does not momentarily exist external to the practical experience of relationality. Rather, his entire existence is without relationality, full stop.

Finally, absent relations with others, we cannot be said to have dignity. Relationality is the condition of the possibility of our fundamental worth as human beings. We are, in essence, dependent upon the presence of and interactions with others for our dignity. Normativity and dignity both necessarily spring forth from this situation of interdependence. Our interdependence is a necessary (though not sufficient) condition of normativity. One might object that the last person on earth could at least engage dignity as a selfreferential concept - such as that of respecting himself or understanding himself to have inherent moral worth. Recall, however, that absent relationality, self-conception and selfunderstanding shrivel, or fail to develop in the first place. And absent such vital instruments, the last person on earth will not be able to form the mechanism of moral selfregard through which he might begin to see his moral self-relation as one of respect.

My aim is still not to say that other's care of us bestows value upon us. I am, instead, commenting on the normative significance of human relatedness itself, rather than what I take to be a more specific moment or variety of that relatedness, namely, care. Care, understood as a dependency relation, is deserving of moral pride of place, as we can see in Bonnie Mann's apt description of care as 'the condition for the possibility of all other human relations, since to come to a point of engaging in any relation, one must first be cared for' (2002, 355-356). If Mann is right, then the dependency relation is constitutive of human relatedness, and dependency relations would require special moral attention and concern (a position with which my overarching argument is in agreement). The scope of my claim incorporates this mode of engagement, but spans beyond it to think about the moral significance of relationality inclusive of, but not exclusive to, dependency. Thus, we return to the notion of dignity as fundamentally grounded in relationality.

A final remark about the relationship of my position to a recent important concept in care ethics, which should help to head off at the pass one final line of objection regarding possible relational foundations for dignity. This is the notion of being 'some mother's child'. In Love's Labor, Eva Feder Kittay tells the story of her how her mother, after serving the rest of the family dinner, would then sit down to eat, noting that she was 'also a mother's child' (1999, 23). Kittay draws from this example the idea that how others have cared for us creates value in us and that our caring for others can do the same for them. The notion of being 'some mother's child' is a powerful one that warrants thorough philosophical attention and exploration. It is not, however, what I am trying to convey with the third intervention. I take the concept of being 'some mother's child' to instead be more closely aligned with the first intervention I considered.

\section{Conclusion}

What I have hopefully accomplished in this article is first to characterize the powers and perils of the concept of dignity and then to offer three forays that care ethics might 
make into current critical, scholarly discussions of dignity. The interventions bring with them both differing intentions and degrees of success. Intervention II, in particular, may need to be left by the wayside (or at least modified such that we can appreciate the moral power of care while keeping a watchful eye on its unintended exclusionary effects). Intervention I draws on care ethics to expand what we understand about dignity in a normative register. Intervention III brings with it the potential to alter how we conceptualize dignity metaethically.

One overall point I hope I have successfully demonstrated, developing on work that a few scholars have already offered, is that the ethics of care has a distinctive and important contribution to make to current scholarly discussions of dignity. And, indeed, that care ethics can shape this concept in novel and useful ways. My work here is intended as a contribution that will hopefully inspire additional, related conversations and efforts in this regard.

\section{Acknowledgements}

I would like to thank Christine Koggel for her astute editorial cultivation of this article. I would also like to thank the anonymous reviewer for their insightful comments. Audiences at two different venues provided valuable feedback on earlier versions of this paper: the American Political Science Association panel on 'Care Ethics, Public Policy, and Human Dignity' and a conference on 'Care in Practice: On the Philosophy and Implementation of Care Ethics' at the University of Sheffield, where Christopher Bennett's comments were especially helpful.

\section{Disclosure statement}

No potential conflict of interest was reported by the author.

\section{Notes}

1. United Nations. 'Universal Declaration of Human Rights'. Accessed December 27, 2016. http:// www.un.org/en/universal-declaration-human-rights/index.html.

2. See related distinctions in Formosa and Mackenzie (2014), Sensen (2011), and Schroeder (2010).

3. While there is some conceptual overlap between the Kantian conception of love as he articulates it here and care as I am using it, it should be noted that they are not one and the same.

\section{References}

Andorno, Roberto. 2013. "The Dual Role of Human Dignity in Bioethics." Medicine, Health Care and Philosophy 16: 967-973.

Baier, Annette. 1987. "Hume: The Woman's Moral Theorist?" In Women and Moral Theory, edited by Eva Feder Kittay and Diana Meyers, 37-55. Totowa, NJ: Rowman \& Littlefield.

Bubeck, Diemut. 1995. Care, Gender and Justice. Oxford: Clarendon Press.

Claassen, Rutger. 2014. "Human Dignity in the Capability Approach." In The Cambridge Handbook of Human Dignity, edited by Marcus Düwell, Jens Braavig, Roger Brownsword, and Dietmar Mieth, 240-249. Cambridge: Cambridge University Press.

Dan-Cohen, Meir. 2002. Harmful Thoughts: Essays on Law, Self, and Morality. Princeton, NJ: Princeton University Press.

Darwall, Stephen L. 1977. "Two Kinds of Respect." Ethics 88 (1): 36-49.

Debes, Remy. 2009. “Dignity's Gauntlet." Philosophical Perspectives 23 (1): 45-78. 
Dillon, Robin S. 1992. "Respect and Care: Toward Moral Integration." Canadian Journal of Philosophy 22 (1): 105-131.

Engster, Daniel. 2004. "Care Ethics and Natural Law Theory: Toward an Institutional Political Theory of Caring." The Journal of Politics 66 (1): 113-135.

Engster, Daniel. 2007. The Heart of Justice: Care Ethics and Political Theory. Oxford: Oxford University Press.

Fanon, Frantz. 2008. Black Skin, White Masks. Translated by Charles L. Markmann. New York: Grove Press.

Formosa, Paul, and Catriona Mackenzie. 2014. "Nussbaum, Kant, and the Capabilities Approach to Dignity." Ethical Theory and Moral Practice 17: 875-892.

Foster, Charles. 2011. Human Dignity in Bioethics and Law. Oxford: Hart.

Gilligan, Carol. 1982. In a Different Voice: Psychological Theory and Women's Development. Cambridge, MA: Harvard University Press.

Goodin, Robert E. 1985. Protecting the Vulnerable: A Re-analysis of Our Social Responsibilities. Chicago, IL: University of Chicago Press.

Held, Virginia. 2006. The Ethics of Care. New York: Oxford.

Kant, Immanuel. 1996. The Metaphysics of Morals. Translated and edited by Mary J. Gregor. Cambridge: Cambridge University Press.

Kittay, Eva Feder. 1999. Love's Labor: Essays on Women, Equality and Dependence. New York: Routledge.

Kittay, Eva Feder. 2011. "The Ethics of Care, Dependence, and Disability." Ratio Juris 24 (1): 49-58.

Kittay, Eva Feder, and Licia Carlson. 2010. Cognitive Disability and Its Challenge to Moral Philosophy. Malden, MA: Wiley-Blackwell.

Leget, Carlo. 2013. "Analyzing Dignity: A Perspective from the Ethics of Care." Medicine, Health Care and Philosophy 16 (4): 945-952.

Macklin, Ruth. 2003. "Dignity is a Useless Concept." British Medical Journal 327: 1419-1420.

Mann, Bonnie. 2002. "Dependence on Place, Dependence in Place." In The Subject of Care: Feminist Perspectives on Dependency, edited by Eva Feder Kittay and Ellen K. Feder, 348-368. Lanham, MD: Rowman \& Littlefield.

Metz, Thaddeus, and Sarah Clark Miller. 2016. "Relational Ethics." In The International Encyclopedia of Ethics, edited by Hugh LaFollette, 1-10. Malden, MA: Wiley-Blackwell.

Miller, Sarah Clark. 2012. The Ethics of Need: Agency, Dignity, and Obligation. New York: Routledge.

Misztal, Barbara A. 2013. "The Idea of Dignity: Its Modern Significance." European Journal of Social Theory 16 (1): 101-121.

Moellendorf, Darrel. 2002. Cosmopolitan Justice. Boulder, CO: Westview.

Noddings, Nel. 1984. Caring: A Feminine Approach to Ethics and Moral Education. Berkeley: University of California Press.

Nussbaum, Martha C. 2006. Frontiers of Justice: Disability, Nationality, Species Membership. Cambridge, MA: Harvard University Press.

Nussbaum, Martha C. 2009. "The Capabilities of People with Cognitive Disabilities." Metaphilosophy 40 (3-4): 331-351.

Ruddick, Sara. 1989. Maternal Thinking: Toward a Politics of Peace. Boston: Beacon Press.

Schroeder, Doris. 2010. "Dignity: One, Two, Three, Four, Five, Still Counting." Cambridge Quarterly of Healthcare Ethics 19 (1): 118-125.

Sensen, Oliver. 2011. Kant on Human Dignity. Berlin: De Gruyter.

Sevenhuijsen, Selma. 1998. Citizenship and the Ethics of Care. New York: Routledge.

Slote, Michael. 2007. The Ethics of Care and Empathy. New York: Routledge.

Tronto, Joan C. 1993. Moral Boundaries: A Political Argument for an Ethic of Care. New York: Routledge. Van Hooft, Stan. 2009. Cosmopolitanism: A Philosophy for Global Ethics. New York: Routledge.

Weinrib, Jacob. 2016. Dimensions of Dignity: The Theory and Practice of Modern Constitutional Law. Cambridge: Cambridge University Press. 